\author{
Volume 1, Issue 1, 2019
}

\title{
Rambu Solo' Menurut Perspektif Eksistensialisme Sartre dalam Masyarakat Modern di Lembang Saloso, Kecamatan Rantepao, Kabupaten Toraja Utara
}

\author{
Rambu Solo 'by Existensialism Perspective Sartre Modern Society in Saloso Village, Rantepao District, \\ North Toraja Regency \\ Glory Tulaktondok ${ }^{1}$, T.R. Andi Lolo ${ }^{2}$, Suparman Abdullah ${ }^{3 *}$ \\ ${ }^{1}$ Mahasiswa Pascasrajana Sosiologi Fisip Universitas Hasanuddin, Makassar, Indonesia, email: \\ glory.tulaktondok@yahoo.com \\ ${ }^{2}$ Dosen Sosiologi Fisip Universitas Hasanuddin, Makassar, Indonesia, email: direks2003@yahoo.com \\ ${ }^{3}$ Dosen Sosiologi Fisip Universitas Hasanuddin, Makassar, Indonesia, email: mansosio87@yahoo.com
}

\section{A R T I C L E I N F O}

\section{How to Cite:}

Tulatoktondok, G., Lolo, T. A., \& Abdullah, S. (2019). Rambu Solo' Menurut Persfektif Eksistensi Sartre dalam Masyarakat Modern di Lembang Saloso, Kecamatan Rantepao, Kabupaten Toraja Utara. Hasanuddin Journal of Sociology (HJS), 1(1), 25-34.

\section{Keywords:}

'Rambu Solo', Sartre

Existentialism, Funeral

\section{Kata Kunci :}

Rambu Solo', Eksistensialisme Sartre, Upacara Kematian

\begin{abstract}
A B S T RA C T
This study aims to obtain a description of the existence of Rambu Solo 'according to the Sartre perspective consisting of a social view of the social strata in the implementation of Rambu Solo' knowledge, enthusiasm, and community appraisal of Solo Rambu's funeral ceremony in Lembang Saloso, Rantepao Sub District, North Toraja District. This study used a convergent mixed approach. Respondents in this study amounted to 78 people and 2 informants namely the community consisting of the head of the family in Lembang Saloso and customary leaders and chairman of the Alliance of Indigenous Peoples of Nusantara (AMAN) Toraja. The sampling technique uses disproportionate stratified random sampling method. Data collection techniques used techniques through questionnaires (questionnaires), observation, semi structured interviews, and documentation studies. The results of this study indicate that the Rambu Solo 'according to Existentialism of Sartre in modern society in Lembang Saloso is in the medium category, indicating that the Rambu Solo' which is done by modern society is current and there are real values of Rambu Solo ' has begun to disappear. This is evidenced from the research focus of the research problem is the view of the social strata in Rambu Solo ', knowledge, enthusiasm, and assessment that fall into the category of being. Therefore, the role of local adat stakeholders is needed in order to strengthen customary values and increase knowledge about the signs of Solo to the people of Lembang Saloso.
\end{abstract}

\section{A B S T R A K \\ Penelitian ini dilatarbelakangi oleh pelaksanaan upacara pemakaman Rambu Solo' di kalangan masyarakat Toraja yang semakin tahun semakin meriah, dan mewah meskipun hal tersebut membutuhkan biaya yang cukup besar, masyarakat tetap berusaha keras untuk dapat melaksanakan upacara}

* Corresponding author. Tel.: 085395443684

E-mail address: glory.tulaktondok@yahoo.com 
pemakaman yang meriah, mewah, dan mahal. Dan Rambu Solo' yang dilakukan masyarakat modern saat ini sudah mulai bersifat kekinian dan ada nilai-nilai adat Rambu Solo' yang sudah mulai ditinggalkan. Penelitian ini bertujuan untuk memperoleh gambaran tentang eksistensi Rambu Solo' menurut perspektif Sartre yang terdiri dari pandangan masyarakat terhadap strata sosial dalam pelaksanaan Rambu Solo', pengetahuan, antusias, dan penilaian masyarakat terhadap upacara pemakaman Rambu Solo' di Lembang Saloso Kecamatan Rantepao Kabupaten Toraja Utara. Penelitian ini menggunakan pendekatan campuran konvergen . Masyarakat dalam penelitian ini berjumlah 78 orang dan 2 orang informan yaitu masyarakat yang terdiri dari kepala keluarga yang ada di Lembang Saloso dan Pemangku adat serta Ketua Aliansi Masyarakat Adat Nusantara (AMAN) Toraja. Teknik Sampling menggunakan metode disproportionate stratified random sampling. Teknik pengumpulan data menggunakan teknik melalui kuesioner (angket), observasi, wawancara semiterstruktur dan studi dokumentasi. Hasil penelitian ini menunjukkan bahwa Rambu Solo' menurut Eksistensialisme Sartre dalam Masyarakat Modern di Lembang Saloso berada pada kategori sedang yang menandakan bahwa Rambu Solo' yang eksis dilakukan oleh masyarakat modern saat ini bersifat kekinian dan ada nilai-nilai adat Rambu Solo' yang sesungguhnya yang sudah mulai hilang. Hal ini dibuktikan dari hasil penilitian fokus masalah penelitian yaitu pandangan terhadap strata sosial dalam Rambu Solo', pengetahuan, antusias, dan penilaian yang masuk dalam kategori sedang. Sehingga diperlukan peranan pemangku adat setempat dalam rangka penguatan nilai-nilai adat dan peningkatan pengetahuan tentang Rambu Solo' kepada masyarakat Lembang Saloso.

(c) 2019 Hasanuddin Journal of Sociology. All rights reserved.

\section{PENDAHULUAN}

Tradisi lokal sebagai elemen yang mendukung citra budaya bangsa, sebagai warisan budaya dan membentuk sikap-sikap budaya harus dipertahankan dan dilestarikan, sehingga budaya tersebut dapat dikenal oleh masyarakat luar. Namun tidak dapat dipungkiri bahwa kompleksitas yang berkembang sebagai akibat dari pelestarian budaya tersebut dapat menimbulkan permasalahan baru bagi kehidupan sosial dan ekonomi keluarga karena terikat dalam batasan adat tersebut.

Masyarakat Toraja mengenal adat Rambu Solo'. Adat Rambu Solo' merupakan adat orang Toraja melalui upacara pemakaman dimana hal ini dilakukan sebagai wujud penghormatan terakhir kepada orang tua yang telah meninggal atas jasa-jasa semasa hidupnya.

Pelaksanaan Rambu Solo' membutuhkan dana yang besar sehingga masalah utama yang dihadapi oleh masyarakat Toraja, khususnya keluarga pelaksana Rambu Solo' adalah masalah keuangan. Hal ini menyebabkan di kalangan masyarakat Toraja ada beberapa keluarga yang menyimpan mayat orang meninggal di dalam rumah hingga berpuluh-puluh tahun untuk disimpan hingga biaya untuk melaksanakan upacara pemakaman Rambu Solo' terkumpul. Selain itu mereka juga rela meminjam uang dari berbagai sumber dalam rangka memenuhi kebutuhan untuk pelaksanaan Rambu Solo' yang 
meriah dan mengeluarkan biaya yang cukup besar. Sikap mereka yang memaksakan kemampuan ekonomi dalam pelaksanaan Rambu Solo' ini dipengaruhi oleh beragam persepsi yang mereka dapatkan dari lingkungannya.

Persiapan dan pelaksanaan upacara Rambu Solo' di kalangan masyarakat Toraja, dapat menghabiskan biaya sampai milyaran rupiah. Meskipun seperti itu masyarakat Toraja tetap melaksanakan dan menjalankan budaya Rambu Solo'. Masyarakat Toraja mempersepsikan upacara Rambu Solo' secara beragam berdasarkan stimulus berupa informasi yang mereka peroleh dari lingkungannya baik melalui penglihatan, pendengaran, penghayatan, dan perasaan. Mereka berpendapat bahwa dalam melaksankan upacara Rambu Solo' pada tingkatan upacara tertentu yang berlaku bagi strata sosial tertentu harus dan wajib dilaksanakan. Selain itu, persepsi masyarakat bahwa pelaksanaan Rambu Solo' dilaksanakan secara meriah dan mahal untuk meningkatkan status dan kedudukan seseorang. Persepsi tersebut menimbulkan pergesaran nilai-nilai budaya yang terkandung dalam upacara Rambu Solo'.

Teori Strate mengenai eksistensialisme menyatakan bahwa manusia adalah bebas; mereka bertanggungjawab terhadap segala sesuatu yang mereka lakukan. Begitu pula dengan masyarakat Toraja dalam melaksanakan upacara Rambu Solo' meskipun sudah ada aturan adat dan nilai-nilai Rambu Solo' yang terbentuk, tetapi masih ada sebagian masyarakat Toraja yang tidak melakukan upacara pemakaman Rambu Solo' sesuai dengan aturan tersebut, mereka melakukannya sesuai dengan keinginan dan kemampuan mereka tanpa melihat kembali aturan dan nilai yang sesungguhnya dalam melaksanakan upacara pemakaman Rambu Solo'. Hal ini dilihat dengan munculnya “Generasi Orang Kaya Baru di Toraja yang berpesta Besar-besaran melebihi kaum darah biru, dianggap telah merusak nilai luhur Rambu Solo' yang Sesungguhnya. Sebenarnya kita harus memahami bahwa roda kehidupan itu berputar, darah di tubuh kita bukan jaminan untuk mendapatkan materi sebanyak-banyaknya melainkan dengan kerja keras, karena generasi saat inilah menunjang agar adat Toraja tetap bertahan dan berjalan. Dari pihak yang tidak mempermasalahkan kelakuan "Generasi Orang Kaya Baru" mengatakan, Fenomena seperti ini adalah perkembangan zaman, apapun itu semua ada masanya seperti adat yang berjalan seiring perkembangan zaman. Sama halnya dulu, belum ada orang yang mengenal agama, bahkan mata pencarian masyarakat masih susah, makanya ada istilah "Diotok ba'tu dipatok tu anggenna ladipogau' “ Sama halnya zaman sekarang mata pencarian atau "Dakaran Kande" orang pintar/orang sukses sudah ada, maka "na patassu' duka tu kadenanna”, dia mengeluarkan juga apa yang di miliki “na pogau' tu misa' sara' ba'tu aluk” ritual rambu solo' sesuai kemampuannya. Dari sisi kontra yang sangat menentang kelakuan "Generasi Orang Kaya Baru di Toraja” turut berkomentar bahwa, zaman sekarang ritual Rambu Solo' sudah jauh melebihi ukuran 
yang semestinya. Istilah kerennya "habis-habisan" sehingga mengancam nilai luhur Rambu Solo' yang sesungguhnya. bukan lagi fokus melaksanakan ritual sesuai tatanannya, tapi ini lebih kepada "Posisinya nanti di masyarakat" sehingga dari sini muncul istilah "Morai di sanga" sampai ada yang berkomentar "tilabe-labe”, siapapun dia kalau mampu dan turut melestarikan budaya perlu diacungi jempol, asal dia berpatokan pada tatanan adat misalnya 24 ekor kerbau. Kalau sudah melebihi dari itu apalagi kalau sudah sampai ratusan, bukan lagi adat tapi pembantaian binatang.

Dalam adat Rambu Solo' kalangan yang bukan bangsawan yang sudah memiliki kemampuan ekonomi yang baik tidak boleh melaksankan Upacara Rambu Solo' yang dilakukan oleh kaum Bangsawan, karena mereka tidak memiliki landasan Tongkonan yang kuat untuk menggelar Upacara Rambu Solo'. Jika tetap melaksanakan Rambu Solo' tingkatan di Rapai' atau melebihi itu maka sifatnya hanya pemborosan dan mengejar prestise belaka. Maka dari itu dengan munculnya "generasi orang kaya baru" di Toraja, maka secara tidak langsung ada sebagian pihak mengajak kita untuk melihat kembali tatanan Ritual Rambu Solo' yang sesungguhnya sesuai status sosialmulah? Atau karena ingin mengikuti tren dalam menjalankan budaya Rambu Solo' yang mewah dan mahal karena tuntutan "prestise"?

\section{BAHAN DAN METODE}

\subsection{Lokasi dan Rancangan Penelitian}

Penelitian ini dilakukan di Lembang Saloso, Kecamatan Rantepao, Kabupaten Toraja Utara. Jenis Penelitian ini menggunakan metode campuran konvergen yaitu metode penelitian yang terdiri dari pengombinasian data kuantitatif dan data kualitatif.

\subsection{Populasi dan Sampel}

Populasi adalah seluruh kepala keluarga yang ada di wilayah Lembang Saloso. Sampel sebanyak 78 orang Kepala Keluarga yang dipilih secara disproportionate stratified random sampling. Kepala keluarga dipilih sebagai masyarakat karena dalam melaksanakan upacara Rambu Solo' semua tanggungjawan dan pengambilan keputusan diberikan kepada kepala keluarga. Terdapat 5 kampung atau dusun yang ada di Lembang Saloso, Kampung Kalamindan merupakan kampung yang banyak masyarakatnya menjadi masyarakat. Peneliti juga mewawancarai dua informan yakni pemangku adat dan ketua Aliansi Masyarakat Adat Nusantara (AMAN) Toraja untuk mendapatkan informasi yan mendukung penelitian ini.

\subsection{Metode Pengumpulan Data}


Metode pengumpulan data yang digunakan dalam penelitian ini adalah dengan menyebar kuesioner atau angket kepada 78 masyarakat, kemudian melakukan studi dokumentasi untuk mengetahui informasi dan data-data yang mendukung penelitian ini. Selain itu peneliti juga melakukan wawancara semiterstruktur kepada dua informan yakni pemangku adat Lembang Saloso dan Ketua Aliansi Masyarakat Adat Nusantara (AMAN) Toraja. Dan peneliti melakukan observasi pengamatan langsung kepada masyarakat pada saat upacara adat Rambu Solo’ di daerah Lembang Saloso.

\subsection{Analisis Data}

Teknik analisis data dalam penelitian ini menggunakan teknik analisis data metode campuran konvergen yaitu dengan menggunakan pendekatan perbandingan berdampingan (side-byside comparison). Peneliti akan terlebih dahulu akan melaporkan hasil statistik kuantitatif dan kemudian membahas temuan kualitatif yang mengonfirmasi atau tidak mengonfirmasi hasil statistik.

\section{HASIL}

\subsection{Pandangan Masyarakat terhadap Strata Sosial dalam Pelaksanaan Rambu Solo'}

Hasil penelitian dari pandangan masyarakat terhadap strata sosial dalam pelaksanaan Rambu Solo' masuk dalam kategori sedang, hal ini dapat dilihat pada gambar 1 yang menunjukkan bahwa perolehan skor hasil fokus penelitian ini yakni sebesar 1.269. Dengan demikian dapat dinyatakan bahwa pandangan masyarakat terhadap tingkat upacara berdasarkan strata sosial dalam upacara pemakaman Rambu Solo' tergolong dalam kategori sedang. Penjelasan kategori sedang disini dimaksudkan bahwa pandangan mereka belum sesuai dengan peraturan dalam pelaksanaan upacara Rambu Solo' yang sesungguhnya.

\subsection{Pengetahuan Masyarakat tentang Rambu Solo'}

Gambar 2 memperlihatkan hasil perolehan skor dari pengetahuan masyarakat tentang Rambu Solo' yang berada pada angka 3.570 dan masuk pada kategori sedang. . Dengan demikian dapat dikatakan bahwa aspek pengetahuan dari masyarakat terhadap upacara pemakaman Rambu Solo' dalam kategori sedang, maka dari itu perlu adanya usaha dalam menigkatkan pengetahuan masyarakat tentang Rambu Solo ' agar tidak terjadi penyimpangan dalam pelaksanaan Rambu Solo'.

\subsection{Antusias Masyarakat terhadap Rambu Solo’}

Berdasarkan gambar 3 dapat dilihat bahwa tingkat antusias masyarakat Lembang Saloso terhadap pelaksanaan upacara Pemakaman Rambu Solo' tergolong dalam kategori sedang. Hal ini dapat dilihat dari perolehan secara keseluruhan dengan skor hasil 1.966. Dengan demikian dapat dikatakan bahwa tingkat antusias dari masyarakat terhadap upacara pemakaman Rambu Solo' dalam kategori sedang, jika dilihat dari garis kontinum yang hampir mencapai tingkat kategori tinggi dapat disimpulkan antusias masyarakat terhapdap pelaksanakaan upacara pemakaman Rambu Solo’ hampir mendekati 
kategori tinggi.

\subsection{Penilaian Masyarakat Terhadap Rambu Solo'}

Berdasarkan gambar 4 maka dapat dikatakan bahwa penilaian masyarakat terhadap upacara pemakaman Rambu Solo' di Lembang Saloso tergolong dalam kategori sedang. Hal ini dapat dilihat dari perolehan skor hasil aspek penilaian sebesar 1.486. Dengan demikian dapat dinyatakan bahwa aspek penilaian masyarakat terhadap pelaksanaan upacara Rambu Solo' tergolong dalam kategori sedang. Hal ini menandakan bahwa penilaian masyarakat tentang Rambu Solo' adalah meskipun bersifat pemborosan secara ekonomi tetapi memiliki makna dan nilai-nilai adat yang dapat menyatukan rumpun keluarga dan sudah menjadi ciri khas orang Toraja.

\section{PEMBAHASAN}

Dalam penelitian ini eksistensi Rambu Solo' yang terjadi dalam masyarakat modern bersifat kekinian, hal ini dibuktikan dengan hasil penelitian eksistensi Rambu Solo’ berada pada kategori sedang yang artinya Rambu Solo' yang dilaksanakan oleh masyarakat modern saat ini tidak terlalu bersifat tradisional dan ada beberapa nilai-nilai adat Rambu Solo' yang sesungguhnya sudah mulai hilang dan nilai-nilai yang diterapkan saat ini bersifat kekinian.

Eksistensi menurut pandangan Sartre didefenisikan dengan dan melalui aksi seseorang, manusia adalah apa yang dilakukan. Bagi Sartre, manusia adalah bebas: mereka bertanggungjawab terhadap segala sesuatu yang mereka lakukan, mereka tidak menyesal jika mereka melakukan kesalahan. (Ritzer,2009:49) Dalam penelitian ini menggunakan perspektif sartre yakni manusia adalah bebas melakukan apa yang mereka lakukan untuk menunjukkan eksistensinya, begitu pula dengan masyarakat modern Toraja dalam melaksanakan upacara pemakaman Rambu Solo'. Masyarakat modern Toraja bebas menentukan pilihan mereka apakah mereka melaksankaan upacara pemakaman Rambu Solo' dengan mengikuti aturan dan nilainilai sesungguhnya atau keluar dari aturan-aturan dan nilai-nilai tersebut. Dan dari pilihan mereka dalam menentukan sikap untuk pelaksanaan Rambu Solo' tersebut kita dapat melihat eksistensi Rambu Solo' yang bersifat modern atau tradisional yang memiliki eksistensi yang kuat di dalam masyarakat modern atau sama-sama memiliki kekuatan untuk tetap eksis baik secara modern maupun tradisional.

Pandangan masyarakat terhadap strata sosial dalam pelaksanaan Rambu Solo' sangat mempengaruhi pelaksanaan Rambu Solo' di dalam masyarakat modern saat ini. Berdasarkan hasil penelitian dari pandangan masyarakat terhadap tingkatan upacara berdasarkan starata sosial adalah masuk dalam kategori sedang, dimana pandangan mereka akan hal ini masih bersifat belum sesuai dengan aturan 
yang sesuai adat Rambu Solo' yang sesungguhnya. Masih banyak masyarakat yang berpendapat bahwa jenis pekerjaan, tingkat pendidikan, tingkat pendapatan serta kepemilikan harta benda dapat mempengaruhi strata sosial seseorang dalam pelaksanaan Rambu Solo', padahal jelas bahwa strata sosial dari masyarakat Toraja didapatkan dari garis keturunan atau ascribed status dan bukan berupa achived status seperti yang dipahami oleh sebagan besar masyarakat. Selain itu sebagian masyarakat masih berpandangan bahwa strata sosial orang Toraja dapat saat melaksanakan upacara Rambu Solo' sesuai dengan tingkatan upacara yang dilaksanakan. Hal ini juga tidak sesuai dengan peraturan adat yang sesungguhnya, strata sosial tidak akan berubah menjadi hamba dan begitupun sebaliknya kaum hamba tidak akan menjadi bangsawan saat melaksanakan Rambu Solo'. Dan melaksanakan Rambu Solo' secara mewah dan meriah juga tidak akan meningkatkan status sosial seseorang. Sebagian masyarakat juga masih berpandangan bahwa kalangan strata sosial bawah yang memiliki kemampuan ekonomi yang baik dapat melakukan tingkatan upacara untuk kaum bangsawan yaitu dirapai yang merupakan tingkatan upacara Rambu Solo 'yang bersifat mewah dan meriah, padahal hal ini sebenarnya tidak diperbolehkan karena keluarga strata kalangan bawah tidak memiliki landasan adat yang kuat seperti tongkonan, kombongan yang menanungi, dan hanya bersifat pemborosan. Seharusnya strata kalangan bawah tetap melaksankan Rambu Solo' sesuai dengan tingkatan upacaranya yaitu di silli' atau di pasang bongi dan tidak boleh meaksankan Rambu Solo' tingkatan di Rapai'. Pandangan-pandangan ini perlu diluruskan oleh pemangku-pemangku adat di Lembang Saloso agar pandangan dan pemahaman dari masyarakat dapat kempali pada jalurnya dan sesuai dengan peraturan adat yang sesungguhnya agar tidak terjadi kesalahapahaman dan pelanggaran dalam pelaksanaan Rambu Solo'. Sehingga makna dari Rambu Solo' sesungguhnya tidak hilang dan tidak bersifat mengejar prestise dan pemborosan saja.

Berdasarkan hasil penelitian dengan melihat tingkat pengetahuan masyarakat terhadap upacara Rambu Solo' yang masih dalam kategori sedang. Masih ada peraturan dan nilai-nilai adat sesungguhnya dari pelaksanaan Rambu Solo ' yang masyarakat belum sepenuhnya diketahui dan dipahami dengan baik oleh masyarakat seperti tingkatan dalam upacara Rambu Solo' jenis kerbau yang disediakan dalam pelaksanaan Rambu Solo' dan peraturan serta nilai lainnya yang akan sangat memperngaruhi sebuah pelaksanaan Rambu Solo' sehingga dibutuhkan peningkatan pengetahuan dan pemberian informasi tentang pelaksanaan Rambu Solo' dan nilai-nilai adat sesungguhnya yang ada pada tradisi Rambu Solo ', agar masyarakat mendapatkan pemahaman yang benar dan bertambahnya pengetahuan mereka terhadap pelaksanaan Rambu Solo' dan nilai-nilai yang ada dalam Rambu Solo'. Dengan memiliki pengetahuan dan pemahaman yang benar terhadap Rambu Solo' maka akan membentuk mereka melaksanakan Rambu Solo' sesuai dengan nilai-nilai adat sesungguhnya yang terkandung dalam Rambu Solo'. 
Dan hasil penelitian dari antusias masyarakat terhadap Rambu Solo' berada pada kategori sedang dan dapat dikatakan antusias mereka cukup tinggi terhadap Rambu Solo'. Masyarakat menyatakan mereka dan keluarga tetap setuju dalam mempertahankan Rambu Solo', meskipun Rambu Solo' membutuhkan banyak biaya, tenaga, dan waktu tetapi sebagian masyarakat tetap setuju untuk melaksanakan Rambu Solo' karena budaya ini sudah menjadi tradisi yang sangat kuat dan sulit ditinggalkan, selain itu motivasi penghormatan terakhir terhadap orang tua dan mengejar prestise juga merupakan faktor-faktor yang membuat masyarakat tetap setuju dan antusias dalam melaksanakan Rambu Solo'. Banyaknya jumlah kerbau yang mereka potong yakni sekitar 1 - 5 ekor saat pelaksanaan Rambu Solo' juga menunjukkan bahwa mereka memiliki antusias yang cukup tinggi terhadap Rambu Solo' dan mereka juga memiliki intensitas waktu yang sering menghadiri dan melaksanakan Rambu Solo'.

Hasil penelitian pada aspek penilaian masyarakat terhadap pelaksanaan upacara pemakaman Rambu Solo' sudah tergolong dalam kategori sedang. Hal ini dapat dillihat berdasarkan hasil penelitian dominan masyarakat menyatakan sesuai dalam aspek penilaian terhadap pelaksanaan upacara pemakaman Rambu Solo'. Adapun beberapa pernyataan dalam aspek penilaian yang didominasi dengan pernyataan sesuai oleh masyarakat yaitu pernyataan bahwa Rambu Solo' bersifat Pemborosan, pernyataan meskipun Rambu Solo' memerlukan biaya yang cukup besar, masyarakat Toraja akan berusaha keras untuk melaksanakan Rambu Solo' meskipun diluar kemampuan ekonminya, pernyataan bahwa Rambu Solo' mempengaruhi kondisi perekonomian keluarga, pernyataan tentang Toraja menjadi primadona pariwisata di Sulawesi Selatan dengan adanya pelaksanaaan upacara pemakaman Rambu Solo'. Dilihat dari hasil penelitian beberapa pertanyaan pada aspek penilaian dimana dominan masyarakat menyatakan bahwa Rambu Solo' bersifat positif karena adanya nilai-nilai gotong royong dan kebersamaan, dan merupakan salah satu aset warisan budaya yag dimiliki oleh orang Toraja, meskipun itu memerlukan biaya yang cukup besar, tetapi hal itulah yang menjadikan pelaksanaan Upacara Rambu Solo' tetap dilestarikan. Pertanyaan tentang prioritas pengeluaran biaya untuk Rambu Solo' atau biaya pendidikan anak-anak dominan masyarakat menyatakan hal tersebut kurang bijaksana. Meskipun masih ada beberapa masyarakat yang masih memprioritaskan pengeluaran biaya untuk Rambu Solo' dibandingkan biaya pendidikan anak. Pertanyaan tentang perasaan masyarakat melakukan Rambu Solo' dominan menyatakan kurang membebani, karena hal tersebut telah menjadi adat dan kebiasaan dari leluhur dan menjadi sebuah identitas bagi orang Toraja. 


\section{KESIMPULAN DAN SARAN}

Secara keseluruhan hasil penelitian ini menggambarkan bahwa Rambu Solo' menurut perspektif eksistensialisme Sartre dalam masyarakat modern di Lembang Saloso dalam kategori sedang yang menandakan bahwa Rambu Solo' yang dilakukan bersifat kekinian dan masih ada nilai-nilai adat Rambu Solo' yang sudah mulai hilang. Hal ini dibuktikan dengan melihat dari keseluruhan empat fokus penelitian yang berada pada kategori sedang. Sehingga perlu adanya usaha dalam mengembalikan nilainilai adat Rambu Solo ' yang sesungguhnya agar makna dari Rambu Solo' tersebut tidak hilang dan tetap dirasakan dan bermanfaat bagi daerah Toraja dan diluar Toraja. Berdasarkan hal tersebut, untuk meningkatkan pengetahuan dan pemahaman serta menguatkan nilai-nilai adat Rambu Solo' dalam masyarakat perlunya peranan dari para pemangku adat dalam memberikan pemahaman nilai-nilai adat Rambu Solo' di setiap keluarga pelaksana Rambu Solo ' agar tidak terjadi kesalahan dan hilangnya nilainilai adat sesungguhnya dalam pelaksanaan Rambu Solo'. Selain itu pemangku adat juga perlu tegas dalam memberikan sanksi jika ada keluarga yang tidak melaksanakan upacara Rambu Solo' sesuai dengan peraturan dan nilai-nilai adat dalam Rambu Solo’.

\section{REFERENCES}

Abidin Z. (2007). Analisis Eksistensial. Jakarta. PT Raja Grafindo Persada

A.Muri Yusuf. (2014). Metode Penelitian Kuantitatif, Kualitatif dan Penelitian Gabungan. Jakarta. Kencana

Arianus M. (2005). Keunikan Budaya Toraja.Rantepao.PT Sulo

Astrid S. (2003). Pengantar Sosiologi dan Perubahan Sosial . Grafindo Persada. Jakarta

Burhan Bungin, 2005, Metodologi Penelitian Kuantitatif, Jakarta: Kencana

Buku Himpunan Pelaksanaan Upacara Rambu Tuka' Rambu Solo Pemerintah Kabupaten Toraja Utara Tahun 2013

Buku Upacara Tradisional (Upacara Kematian) Daerah Sulawesi Selatan Departemen Pendidikan dan Kebudayaan Tahun 1984.

Damaris Pare. (2009). Pengaruh Budaya Pesta Rambu Solo’’ Terhadap Kehidupan Keluarga Miskin di Kelurahan Bori' Kecamatan Sesean Kabupaten Toraja Utara. Bandung : Sekolah Tinggi Kesejahteraan Sosial

Dwi Cahyono.(2014). Keberfungsian Keluarga Strata Bangsawan Tertinggi (Tana' Bulaan) dalam Pelaksanaan Rambu Solo' (Upacara Kematian) Tingkatan Dirapai' di Kelurahan Laang Tanduk Kecamatan, Rantepao, Kabupaten Toraja Utara. Bandung : Sekolah Tinggi Kesejahteraan Sosial

Frans Palebangan. (2007). Aluk, Adat, dan Adat-Istiadat Toraja. Rantepao : PT Sulo

Gazalba,Sidi. (1983).Pengantar Kebudayaan Sebagai Ilmu. Jakarta : Pustaka Antara

George Ritzer.2009. Teori Sosial Postmodern. Yogyakarta: Kreasi Wacana

Herimanto dan Winarno. 2017. Ilmu Sosial dan Budaya Dasar. Jakarta:Bumi Aksara

John W.C. (2017) .Research Design Pendekatan Metode Kualitatif, Kuantitatif dan Campuran.Yogyakarta.Pustaka Pelajar

Marwing. (2011). Problem Psikologis dan Strategi Coping Pelaku Upacara Rambu Solo' di Toraja (Studi Fenomenologi pada Tana'Bulaan). Yogyakarta. Program Pasca Sarjana Universitas Gadjah Mada. PSIKOISLAMIKA. Jurnal Psikologi Islam (JPI) Vol. 8 No.2 Januari 2011 
Nanang Martono.(2011) Sosiologi Perubahan Sosial. Jakarta: PT. Raja Grafindo Persada

Roby Panggara. (2014). Konflik dalam Kebudayaan Menurut Teori Lewis Alfred Coser dan Relevansinya dalam Upacara Pemakaman Rambu Solo' di Tana Toraja. Program Pascasarjana STT Jaffray Makassar. Jurnal Jaffray Vol. 12 No, 2 Oktober 2014.

Soerjono Soekanto. (2012). Sosiologi Suatu Pengantar. Jakarta : PT. Raja Grafindo Persada

Sugiyono. (2007). Metode Penelitian Kuantitatif Kualitatif dan R\&D. Bandung: Alfabeta

_. (2008). Metode Penelitian Kuantitatif Kualitatif dan R\&D. Bandung: Alfabeta

,_.(2011). Metode Penelitian Kuantitatif Kualitatif dan R\&D. Bandung: Alafabeta

,_.(2016). Metode Penelitian Kombinasi (Mixed Methods) Bandung: Alafabeta

Suratman, Munir,Umi Salamah. 2015. Ilmu Sosial Budaya Dasar. Malang. Intimedia

Sri Rahayu Djatimurti Rita Hanafie.2016. Ilmu Sosial Budaya Dasar. Yogyakarta.Penerbit Andi

Theodorus Kobong. (2008). Injil dan Tongkonan. Jakarta : BPK Gunung Mulia

Y.A.Sarira. (1996). Aluk Rambu Solo' dan Persepsi orang Kristen terhadap Rambu Solo'. Rantepao:Percetakan Sulo Gereja Toraja 